\title{
Microbial analysis of commercially available US Queso Fresco
}

\author{
Maxwell J. Holle, ${ }^{1}$ Luis A. Ibarra-Sánchez, ${ }^{1}$ Xiaoji Liu, Matthew J. Stasiewicz, and Michael J. Miller ${ }^{2}$ \\ Department of Food Science and Human Nutrition, University of Illinois Urbana-Champaign, Urbana 61801
}

\begin{abstract}
Queso Fresco (QF), a fresh Hispanic-style cheese, is often associated with Listeria monocytogenes outbreaks and recalls. Queso Fresco's susceptibility to bacterial contamination is partially due to its high $\mathrm{pH}$ and moisture content as well as Listeria's tolerance for the salt content typical for QF. Nine different brands of US QF, 2 packages from 4 different lots (to account for temporal variability), were sampled. The $\mathrm{pH}$, salt content, and moisture content were analyzed in addition to microbial testing including yeasts and molds, coliforms, lactic acid bacteria enumeration, and L. monocytogenes counts. The cheeses were also inoculated with a cocktail of 5 food and human isolates of food-borne outbreakassociated Listeria monocytogenes strains to evaluate how the differences between brands influenced Listeria growth. Three of the cheeses underwent additional genus-level microbial analysis using extracted 16S rDNA, allowing for phylogenetic analysis between bacterial taxa including diversity and relative abundance. We found little variation between the sampled $\mathrm{QF} \mathrm{pH}$ (range = 6.62-6.86), salt content (1.53-2.01\%), and moisture content (43.90-54.50\%). Yeasts and molds were below the detection limit of enumeration in all of the cheeses and coliforms were below the detection limit across the first 3 lots, but were detected at varying levels in the fourth lot (>3.0 most probable number/g) for 3 of the brands. Listeria monocytogenes was not isolated after enrichment in any of the samples. All cheeses tested positive for the presence of lactic acid bacteria, with only 1 of the cheeses being labeled as produced with added cultures having substantial counts. Fourteen days after inoculation with $L$. monocytogenes, at least $2.5 \log 10 \mathrm{cfu} / \mathrm{g}$ of growth was found for all QF brands stored at $4^{\circ} \mathrm{C}$. Microbial genus analysis showed that, among the 3 brands, the microbial community was more similar within brand than when compared with the other 2 brands. Thermus, Anoxybacillus, and Strep-
\end{abstract}

Received October 23, 2017.

Accepted May 28, 2018.

${ }^{1}$ These authors contributed equally to this work.

${ }^{2}$ Corresponding author: mille216@illinois.edu tococcus accounted for the dominant genera of brands $\mathrm{A}, \mathrm{B}$, and $\mathrm{C}$, respectively. These variations within the microbial community may account for sensory differences and help manufacturers determine quality control consistency more readily than culture-based methods.

Key words: Listeria monocytogenes, Queso Fresco

\section{INTRODUCTION}

The combination of the increasing Hispanic population in the United States (US Census Bureau, 2017) and an increased cultural introduction to the culinary styles of Latin America has increased the purchasing and consumption of Hispanic foods, as reflected by the increased production of Hispanic-style cheese (HSC) in the United States (USDA-NASS, 2016). Queso Fresco (QF) is a fresh HSC that is traditionally uncultured. Unlike a lot of cheeses, QF possesses a characteristic salt content, high moisture content, and near neutral $\mathrm{pH}$. These characteristics can create a hospitable environment for microbial growth. Despite typically being consumed fresh, QF requires refrigeration to be safely preserved for up to a few weeks.

Dairy products and ready-to-eat foods are the most commonly associated foods with listeriosis (Batz et al., 2011). In particular, listeriosis has been frequently associated with HSC in the United States, with QF being recently recalled in 2014 and 2015 (CDC, 2017a). Unfortunately, Listeria monocytogenes can grow in QF under refrigeration, which greatly contributes to the problem (Leggett et al., 2012; Van Tassell et al., 2015). Immunocompromised and elderly adults, as well as children and pregnant women, are generally the groups that are of the greatest concern, with the greatest risk associated with pregnant Hispanic women due to their increased susceptibility and high consumption frequency (CDC, 2017b).

Pasteurization is an effective process of eliminating $L$. monocytogenes from milk. However, L. monocytogenes contamination during QF manufacturing and postpackaging are of particular concern, as L. monocytogenes has been shown to be persistent in manufacturing settings, including HSC manufacturing facilities (Hnosko et al., 2012; Ferreira et al., 2014), as well as domestic 
Table 1. The distribution of lots for each cheese brand and analysis ${ }^{1}$

\begin{tabular}{|c|c|c|c|c|c|c|}
\hline Brand & Collected & $\begin{array}{l}\text { Selective chemical } \\
\text { characterization }\end{array}$ & $\begin{array}{l}\text { Microbial } \\
\text { analysis }\end{array}$ & $\begin{array}{c}\text { Lactic acid } \\
\text { bacteria }\end{array}$ & $\begin{array}{l}\text { Listeria monocytogenes } \\
\text { challenge }\end{array}$ & $\begin{array}{l}\text { Microbiome } \\
\text { analysis }\end{array}$ \\
\hline $\mathrm{A}$ & $1-4$ & 2,4 & $1-4$ & 2 & 4 & $1-4$ \\
\hline B & $1-4$ & 2,4 & $1-4$ & 2 & 4 & $1-4$ \\
\hline D & $1-4$ & 2,4 & $1-4$ & 2 & 4 & - \\
\hline E & $1-4$ & 2,4 & $1-4$ & 2 & 4 & - \\
\hline $\mathrm{F}$ & $1-4$ & 2,4 & $1-4$ & 2 & 4 & - \\
\hline Z & 4 & 4 & 4 & - & 4 & - \\
\hline
\end{tabular}

${ }^{1}$ Due to availability, 1 to 4 lots were collected, with 2 cheeses per lot, from each brand.

refrigerators (Kilonzo-Nthenge et al., 2008; Macías-Rodríguez et al., 2013). Consequently, antimicrobials that address postpasteurization contamination are needed to completely ensure the safety of QF (Ibarra-Sánchez et al., 2017).

The microbial population of different foods is influenced by the raw ingredients and environmental factors present during processing (Bokulich and Mills, 2013). The microbial community of industrially produced foods are characterized by a relatively simple community (Ercolini, 2013), which may affect pathogen growth upon contamination (Montel et al., 2014). Principal coordinate analysis has been used in other foods and cheeses to evaluate the microbial communities (Quigley et al., 2012; Aldrete-Tapia et al., 2014; Wolfe et al., 2014). By analyzing the phylogenic differences between the bacteria present across lots, a manufacturer may glean insights into processing consistency in that the lots will cluster based on phylogenetic distances and, thus, possibly reveal process deviations.

The objective of our study was to quantify a selection of chemical characteristics pertinent for microbial growth as well as to compare the microbial communities present in commercially available QF. Multiple QF of different brands and lots were purchased from local retailers in central Illinois, and their $\mathrm{pH}$, salt content, and moisture content were determined. The cheeses were tested for L. monocytogenes, coliforms, yeast and molds, and lactic acid bacteria (LAB) counts. Bacterial microbiota was examined by profiling the $16 \mathrm{~s}$ rRNA gene in a subset of cheeses. Finally, the cheeses underwent a Listeria growth challenge to determine if any of the differences among the brands would affect Listeria growth.

\section{MATERIALS AND METHODS}

\section{Cheese Sample Collection}

A total of $64 \mathrm{QF}$ samples from 9 commercial QF brands, labeled A through $\mathrm{F}$ and $\mathrm{X}$ through $\mathrm{Z}$ (Table
1), were purchased from different supermarkets in central Illinois over a 7-mo period. All of the QF brands available in central Illinois were sampled. At least 3 of the brands are nationally available in the United States. For brands A through F, we were able to get 4 distinct lots. For brands X through $\mathrm{Z}$, we were unable to acquire 4 distinct lots due to local unavailability, but they are included in the analysis where indicated. Two cheeses were purchased from each lot per brand, and packages were considered to be from the same lot if they shared the same lot number on their packaging. Duplicate cheeses were purchased at the same time before being transported to the laboratory on ice and held at $4^{\circ} \mathrm{C}$. Analyses were conducted within $48 \mathrm{~h}$ after purchasing.

\section{Selective Chemical Analysis}

Queso Fresco samples from the second and fourth manufacturing lots collected were analyzed in duplicate. Three cheese portions were taken from each QF block using a stainless steel spatula by making radial cuts, and then all portions from the same cheese block were cut finely and mixed thoroughly. Moisture content was determined gravimetrically by drying 2 -g samples in an oven at $105^{\circ} \mathrm{C}$ to constant weight (method 926.08; AOAC International, 2012). To determine the salt content, $1 \mathrm{~g}$ of sample was homogenized in $10 \mathrm{~mL}$ of deionized water, the mixture was centrifuged at 4,000 $\times g$ for $30 \mathrm{~min}$ at $20^{\circ} \mathrm{C}$, and the supernatant was titrated with $0.1 \mathrm{~N} \mathrm{AgNO}_{3}$ in the presence of $\mathrm{K}_{2} \mathrm{CrO}_{4}$ (method 935.43; AOAC International, 2012). For $\mathrm{pH}$ determination, $1 \mathrm{~g}$ of sample was macerated in $10 \mathrm{~mL}$ of deionized water and the $\mathrm{pH}$ was measured by using a $\mathrm{pH}$ meter (Mettler Toledo, Columbus, OH; method 981.12; AOAC International, 2012).

\section{Microbial Analysis}

Individual cheese samples were tested for $L$. monocytogenes according to the FDA-Bacteriological Ana- 
lytical Manual standard enrichment/recovery method, with some modifications (Hitchins et al., 2017). Briefly, 25-g samples (shaped radial sections) of each cheese were diluted 1:10 in modified Listeria enrichment broth (Difco, Franklin Lakes, NJ) supplemented with 1.1 $\mathrm{g} / \mathrm{L}$ of sodium pyruvate. Homogenized samples were incubated at $30^{\circ} \mathrm{C}$ for $48 \mathrm{~h}$, followed by selection on PALCAM agar plates (EMD Millipore, Billerica, MA), and incubated at $37^{\circ} \mathrm{C}$ for $48 \mathrm{~h}$. After incubation, the plates were examined for typical black colonies with a halo (esculin positive), and results were expressed as positive or negative for recovery. Simultaneously, each cheese sample was tested for coliforms, yeast and molds, and LAB counts. Representative 5-g portions (shaped radial sections) of each sample were homogenized with $45 \mathrm{~mL}$ of PBS buffer for $1 \mathrm{~min}$ with a Stomacher 80 Biomaster (Seward, Bohemia, NY), and serial dilutions were prepared. Coliforms were tested by 3 -tube most probable number (MPN) method, first by inoculating serial dilutions of cheese samples into lauryl tryptose broth (Difco) followed by confirmation with brilliant green lactose bile (Difco) broth (Feng et al., 2002). Yeasts and molds were enumerated by spread plating onto dichloran rose bengal chloramphenicol agar (Difco) following incubation at $25^{\circ} \mathrm{C}$ for $5 \mathrm{~d}$ (Tournas et al., 2001). Lactic acid bacteria were quantified by enumeration on MRS (Difco) or M17 agar (Difco) and incubated at $37^{\circ} \mathrm{C}$ for $48 \mathrm{~h}$. The M17 agar and MRS agars were used for isolation and enumeration of lactic streptococci and Lactobacillus, respectively. Lactic acid bacteria enumeration data are presented in $\log _{10}$ colony-forming units per gram and coliform data are presented as MPN per gram.

\section{Listeria monocytogenes Growth in QF}

Three random shaped radial sections of each QF sample were milled and mixed, and 3 representative 5 -g milled portions from each cheese block were collected from the fourth lot of each brand (excluding $\mathrm{X}$ due to brand availability) and placed in individual sterile sample bags. Milled cheese portions were inoculated with approximately $4 \log _{10} \mathrm{cfu} / \mathrm{g}$ of a cocktail of food and human isolates of food-borne outbreak-associated L. monocytogenes, including 1 strain associated with a QF outbreak (Agricultural Research Service Culture Collection Northern Regional Research Laboratory strains B-33104, B33419, B-33420, B-33424, and B-33513). Samples were milled before inoculation to distribute the inoculum among all cheese particles and were not molded back into cheese bricks, as the growth of Listeria in QF is independent of the inoculation method (Van Tassell et al., 2017; Ibarra-Sánchez et al., 2018). Inoculated QF milled samples were mixed with a Stomacher 80 Biomaster and stored at $4^{\circ} \mathrm{C}$. Cheeses were sampled after storage at $4^{\circ} \mathrm{C}$ for 0,7 , and 14 d. Listeria monocytogenes cells were enumerated by spread plating on PALCAM Listeria-Selective agar supplemented with $20 \mu \mathrm{g} / \mathrm{mL}$ of ceftazidime (VWR International, Radnor, PA). Plates were incubated at $37^{\circ} \mathrm{C}$ for $48 \mathrm{~h}$.

\section{Cheese Bacterial Microflora Profiling by IIlumina 16S rRNA Gene Sequencing}

To compare intra- and interlot microbial compositions between brands, total DNA was extracted from $200 \mathrm{mg}$ of cheese (Table 1; 8 samples of A, 8 samples of B, 6 samples of C) using QIAmp DNA stool Mini Kit (Qiagen, Hilden, Germany) with bead-beating ( $\mathrm{Yu}$ and Morrison, 2004; Barry et al., 2009). The DNA libraries were quantified using Qubit dsDNA HS Assay Kit (Thermo Fisher Scientific, Waltham, MA). The 16S rRNA gene sequencing was performed by the DNA Sequencing Group at the Roy J. Carver Biotechnology Center, University of Illinois, using primers that amplified the V3-V5 variable regions of the $16 \mathrm{~S}$ rDNA (Liu et al., 2017; Muturi et al., 2017), and the demultiplexed paired reads were stitched using IM-TORNADO pipeline (version 2.0.3.2; Jeraldo et al., 2014).

Further data analysis, including the generation of distance comparison boxplots (Figure 1B), was performed through the QIIME pipeline (Caporaso et al., 2010) and operational taxonomic unit picking was performed against SILVA ribosomal RNA database (release 128; Quast et al., 2013). The phylogenetic distance between sets of bacterial taxa in each cheese sample, including bacterial diversity and abundance, were measured by the weighted unique fraction metric (UniFrac). Principal coordinates analysis was performed to summarize the dissimilarity between the microbiota communities of each sample and plotted in R (Lê et al., 2008). The box and whisker plots were created using the UniFrac distances to compare distances within brands (comparing each individual package to all of the other packages of the same brand), between brands (comparison of each individual package to all of the packages from the other 2 brands), and within lots (the distance between an individual package and the other package from the same lot across all brands).

The Chao1, Shannon, and Simpson indices were used to measure the dissimilarity of microbiota community within each brand of cheese ( $\alpha$-diversity). Chao1 was used to evaluate the richness of total bacterial taxa in each brand, the Shannon index was used to evaluate the abundance and evenness of the bacterial taxa, and the Simpson index was used to evaluate the relative abundance of each taxon. 
(A)

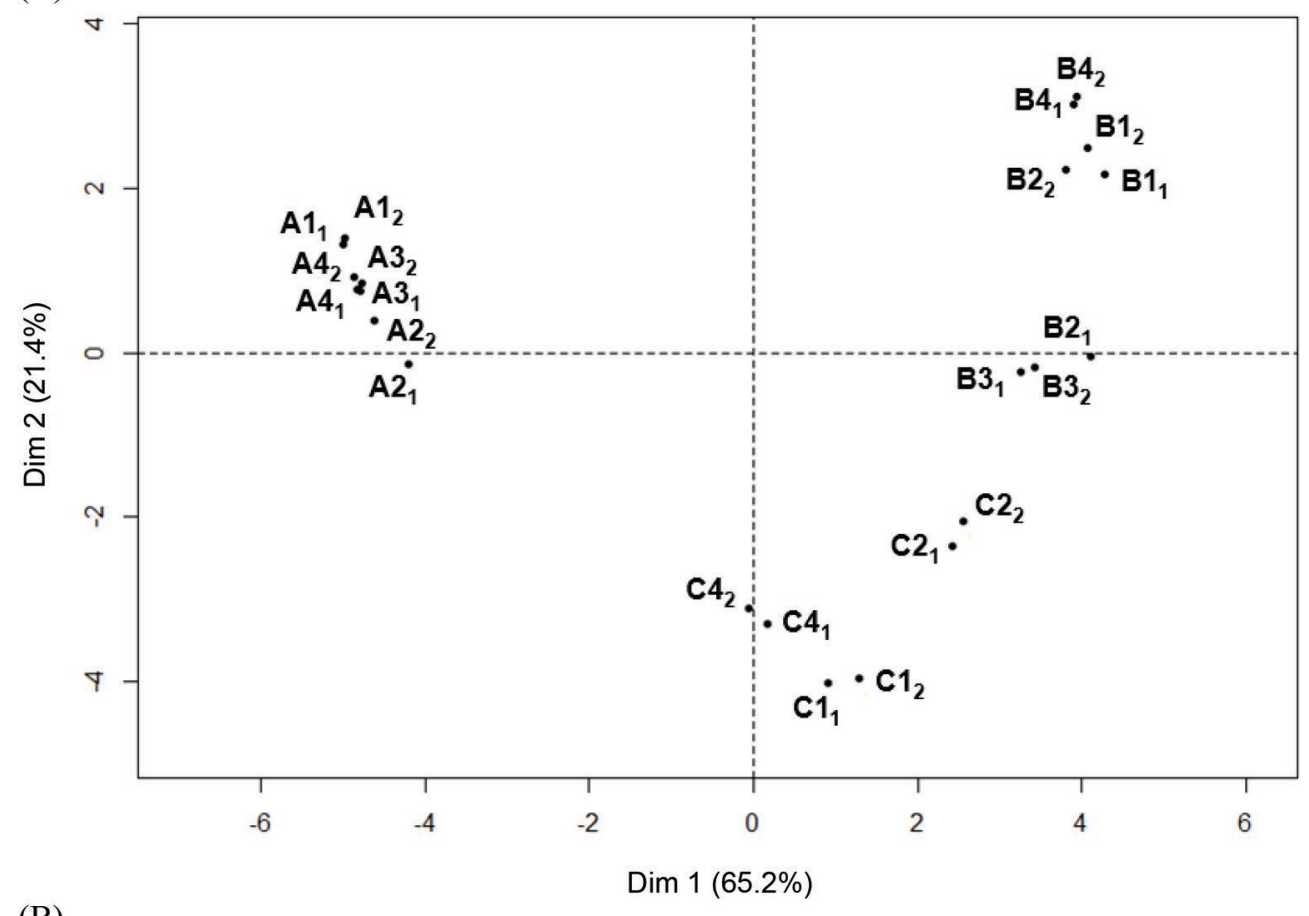

(B)

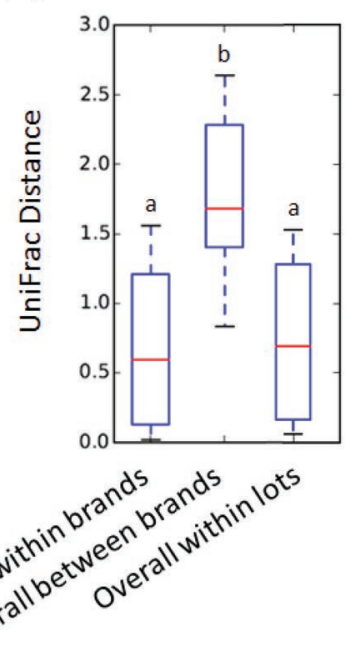

Figure 1. The microbial communities in the sampled Queso Fresco. (A) Principal coordinate analysis plot with 2 dimensions (Dim 1 and Dim 2) was generated based on weighted unique fraction metric, which represents the diversity and abundance of bacteria. The capitalized letters (A-C) represent the brands, numbers 1 to 4 represent different lots, and the subscripts $(1,2)$ indicate different packages of cheese taken from the same lot. (B) Weighted unique fraction (UniFrac) metric distances describing the dissimilarity within each brand, between all 3 brands, and within lot. Boxes: top $=$ third quartile; bottom $=$ first quartile; midline $=$ median. Whiskers: top $=$ maximum; bottom $=$ minimum. Lowercase letters $(\mathrm{a}, \mathrm{b})$ show statistical significance $(P<0.05)$. Color version available online.

\section{Statistical Analysis}

The Kruskal-Wallis analysis with Dunn's multiple comparison test was used to compare the $\alpha$-diversity indices of the microbiota for brands A, B, and C. Analyses were performed using GraphPad Prism version 7.03 (GraphPad Software, La Jolla, CA).

\section{RESULTS AND DISCUSSION}

\section{Selective Chemical and Microbiological Analysis}

Cheese $\mathrm{pH}$, salt content, and moisture content were all determined from 2 different lots from each brand (Table 1). The sampled cheeses showed little variation 
for these attributes (Table 2). In regards to the cheeses made with cultured milk or added cultures (brands $\mathrm{A}, \mathrm{D}, \mathrm{X}$, and $\mathrm{Z}$ ), it has been shown that lactic acidproducing starter cultures can lower the $\mathrm{pH}$ of Latinstyle cheeses during cold storage (Campagnollo et al., 2018). We can only extrapolate the relative age of the cheeses from the labeled expiration dates where, of the aforementioned cheeses, the cheeses from brand A were the farthest from its expiration date and the cheeses from brand $\mathrm{X}$ were the closest; however, the $\mathrm{pH}$ for brand $\mathrm{X}$ was 0.14 higher than brand $\mathrm{A}$. Our results might suggest that the starter cultures used in the analyzed QF were poor acid producers in QF. Overall, the weight percent of $\mathrm{NaCl}$ and moisture content (1.53-2.01 and $43.90-54.50 \%$, respectively) showed little variation among all collected brands. Queso Fresco is reported to have significant variation depending upon the manufacturer, with approximate values of $\mathrm{pH} \geq 6.1,1$ to $3 \%$ salt content, and 46 to $57 \%$ moisture content (Van Hekken and Farkye, 2003), yet the sampled cheeses in our study were less variable despite being produced by 9 different manufacturers. It is important to note that there is no standard of identity for QF in the United States (Ibarra-Sánchez et al., 2017).

The cheeses all tested positive for the presence of LAB on both M17 and MRS agar (Table 2). Brands A, D, $\mathrm{X}$, and $\mathrm{Z}$ were labeled as made with cultured milk, and only B was labeled as containing cultures. The labels did not specify the identities of the cultures. However, of these cheeses (A, D, X, Z, and B), only cheese D had high cell counts on M17 and MRS plates. Additionally, brands A, B, X, and Z all had fewer cell counts than the cheeses that did not label the addition of any cultures. The LAB cultures have been shown to lyse rapidly in cheese (Fox et al., 2017) and, additionally, the amount of salt and the cooking temperature can influence their lysis, resulting in lower starter culture cell counts from the initial inoculum (Hnosko et al., 2008; Fox et al., 2017). On the contrary, adventitious LAB (LAB that were not intentionally added) lyse slowly, are more tolerant to cooking temperatures, and grow rapidly in high moisture cheeses (Fox et al., 2017). The differences in the presence of added LAB cultures and adventitious LAB may account for the observed LAB cell counts, with high cell counts in noncultured cheeses and low cell counts in cultured cheeses (except brand D). Levels of LAB between 2 and $9 \log _{10} \mathrm{cfu} / \mathrm{g}$ on M17 and MRS agar have been reported in other industrial HSC made with and without cultures added (Saxer et al., 2013). Cheese manufacturers may add attenuated LAB cultures (slow growing, no lactic acid production, but enzyme producers; Bevilacqua et al., 2017), as in brand $\mathrm{B}$, to their cheeses in the hopes of flavor development, which may be the case for QF. Commercial companies such as International Media and Cultures (Denver, CO) and SACCO (Cadorago, Italy) offer attenuated cultures that can be used for QF manufacture and other Mexican cheeses.

Yeasts and molds were below the detection limit of enumeration $\left(<2 \log _{10} \mathrm{cfu} / \mathrm{g}\right)$ for all of the cheese samples from all 4 lots of each cheese. Using the MPN method to quantify the coliforms from all 4 lots, the cheeses in lots 1 to 3 all resulted in $<3.0 \mathrm{MPN} / \mathrm{g}$. In the fourth lot, only the cheeses from brand Y $(>1,100$ and 240 $\mathrm{MPN} / \mathrm{g}$ ) and brand Z (240 and $23 \mathrm{MPN} / \mathrm{g}$ ), as well as 1 of the cheeses from brand A (9.2 MPN/g), had detect-

Table 2. Chemical characterization and microbial analysis of 9 different brands of Queso Fresco ${ }^{1}$

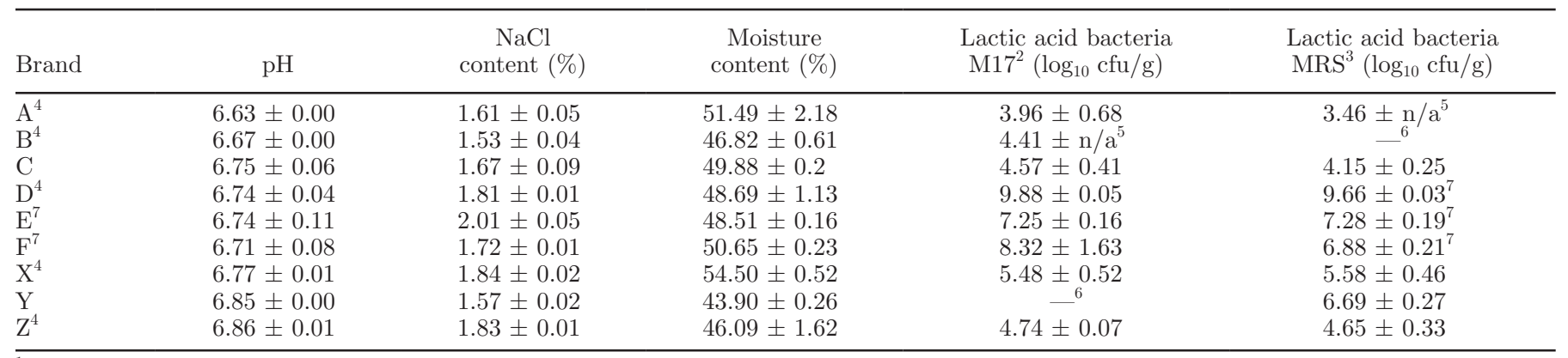

${ }^{1}$ Values are means \pm SEM.

${ }^{2} \mathrm{M} 17$ agar is recommend for use in isolation, enumeration, and cultivation of lactic streptococci in dairy products.

${ }^{3}$ de Man, Rogosa, and Sharpe (MRS) agar is recommended for use in isolation, enumeration, and cultivation of Lactobacillus.

${ }^{4}$ Labeled as cultured milk or added cultures.

${ }^{5}$ One cheese sample had enumerable cell counts. $\mathrm{n} / \mathrm{a}=$ not available.

${ }^{6}$ Enumeration data unavailable.

${ }^{7}$ Potassium sorbate added. 
able coliforms. Others reported values for the coliforms present in pasteurized milk QF from Mexico, with an average of $4.6 \log _{10} \mathrm{cfu} / \mathrm{g}$ (Renye et al., 2008). The microbial limits for QF are defined in Mexico in the Norma Oficial Mexicana as $\leq 100 \mathrm{cfu} / \mathrm{g}$ of coliforms and $\leq 500$ $\mathrm{cfu} / \mathrm{g}$ of yeasts and molds (Secretaria de Salud, 2010); however, in the United States, the microbial guidelines for cheeses are suggested by the National Committee on Microbial Criteria for Foods as $<100 \mathrm{cfu} / \mathrm{g}$ of coliforms and $<10 \mathrm{cfu} / \mathrm{g}$ of Escherichia coli (NACMCF, 2015). We found no discernable differences in the fourth lot of brand Y compared with the other cheeses, despite having the highest coliform count. The association between coliforms and cheese characteristics, such as $\mathrm{pH}$ and water activity, have been previously analyzed (Trmčić et al., 2016), but these associations have only been established for categories of cheeses and not for specific types of cheese. Additionally, specific coliform counts for QF are not reported within US sampling studies, making within-US comparisons unavailable; however, reputable manufacturers would want to be cognizant of any coliform issues. The fourth lot coliform variation could have been due to postprocessing contamination or mishandling as well as the time year the milk was collected (Gillespie et al., 2012). Additionally, all 64 cheeses sampled were negative for $L$. monocytogenes after enrichment.

\section{Listeria Challenge}

To determine if the addition of cultures (brands A, $\mathrm{B}, \mathrm{D}$, and $\mathrm{Z}$ ) or preservatives (brands $\mathrm{E}$ and $\mathrm{F}$ ), by some QF brands collected, affected postmanufacturing L. monocytogenes contamination, the cheeses were inoculated with a cocktail of $L$. monocytogenes strains. This cocktail, including strains associated with foodborne illness outbreaks, grew on all of the sampled cheeses during storage at $4^{\circ} \mathrm{C},(\mathrm{n}=16,8$ duplicate cheeses). All cheeses were contaminated with a similar initial inoculum of L. monocytogenes cocktail (Table 3). After $7 \mathrm{~d}$ of cold storage, L. monocytogenes grew at least $1 \log _{10} \mathrm{cfu} / \mathrm{g}$ in all QF samples. Fourteen days after inoculation, we found approximately a $1 \log$ difference between the highest Listeria population (brand $\mathrm{D}, 7.27 \pm 0.05 \log _{10} \mathrm{cfu} / \mathrm{g}$ ) and the lowest (brand C, $\left.6.19 \pm 0.08 \log _{10} \mathrm{cfu} / \mathrm{g}\right)$ in the cheeses. The highest Listeria population was found in 2 cheeses labeled as having added cultures. Potassium sorbate, a chemical additive used in brands $\mathrm{E}$ and $\mathrm{F}$, did not have any apparent effect on Listeria growth. However, even with a 50-d difference in expiration date, the cell counts of Listeria were similar between the cheese farthest from its expiration date (brand A) and the cheese closest to its expiration date (brand Y).

Greater growth would be expected if the temperature fluctuated to a higher temperature or if the cheeses were examined after a longer time (Mendoza-Yepes et al., 1999). A higher concentration of L. monocytogenes in the consumed food product will result in more illnesses (Buchanan et al., 1997), highlighting the need for antimicrobials that can, at a minimum, prevent $L$. monocytogenes from growing over QF shelf life. It is not surprising that the sampled QF were a suitable substrate for Listeria growth, considering that approximately $20 \%$ of listeriosis outbreaks are associated with high-moisture HSC (Ibarra-Sánchez et al., 2017). We have recently determined that combined treatment of nisin and PlyP100 (an endolysin) can dramatically reduce the Listeria population during refrigerated storage, suggesting that a preservative approach could dramatically reduce the number of listeriosis outbreaks (IbarraSánchez et al., 2018). Many studies have analyzed $L$. monocytogenes growth to different chemical compositions in Mexican style cheeses and QF (Genigeorgis et al., 1991; Bolton and Frank, 1999); however, due to the lack of variation in the assessed chemical characteristics of the sampled QF in our study, little can be extrapolated in regard to whether any differences in these factors account for the observed differences in fold change (Table 3). It would be interesting to manufacture QF with greater variation, within the acceptable limits of QF compositional identity, to ascertain the effect that these factors have on L. monocytogenes growth. These results not only highlight the high-risk factor associated with contamination of $\mathrm{QF}$, but also demonstrate

Table 3. Growth of Listeria monocytogenes in commercial Queso Fresco stored at $4^{\circ} \mathrm{C}$

\begin{tabular}{lccc}
\hline & \multicolumn{3}{c}{ Cell count ${ }^{1}\left(\log _{10} \mathrm{cfu} / \mathrm{g}\right)$} \\
\cline { 2 - 4 } Brand & $\mathrm{d} 0$ & $\mathrm{~d} 7$ & $\mathrm{~d} 14$ \\
\hline $\mathrm{A}^{2}$ & $3.71 \pm 0.14$ & $5.38 \pm 0.16$ & $6.70 \pm 0.65$ \\
$\mathrm{~B}^{2}$ & $3.63 \pm 0.05$ & $5.00 \pm 0.11$ & $7.03 \pm 0.08$ \\
$\mathrm{C}$ & $3.69 \pm 0.01$ & $4.78 \pm 0.04$ & $6.19 \pm 0.08$ \\
$\mathrm{D}^{2}$ & $3.75 \pm 0.06$ & $5.22 \pm 0.01$ & $7.27 \pm 0.05$ \\
$\mathrm{E}^{3}$ & $3.73 \pm 0.12$ & $4.86 \pm 0.16$ & $6.22 \pm 0.22$ \\
$\mathrm{~F}^{3}$ & $3.72 \pm 0.01$ & $5.00 \pm 0.17$ & $6.63 \pm 0.08$ \\
$\mathrm{Y}$ & $3.70 \pm 0.10$ & $5.00 \pm 0.00$ & $6.42 \pm 0.12$ \\
$\mathrm{Z}^{2}$ & $4.76 \pm 0.15$ & $6.70 \pm 0.09$ \\
${ }^{1}$ Values are means \pm SEM. \\
${ }^{2}$ Labeled as cultured milk or added cultures. \\
${ }^{3}$ Potassium sorbate added. \\
${ }^{4}$ L. monocytogenes could not be enumerated accurately due to back- \\
ground bacteria.
\end{tabular}


the need for manufacturing and antimicrobial interventions to address Listeria's propensity for growth in QF.

\section{Cheese Microbiota Community}

To evaluate the microbial communities of randomly selected brands, a subset of cheeses (A, B, and C) were profiled with Illumina MiSeq (Illumina Inc., San Diego, CA), resulting in an average of 15,210 paired-end highquality reads per sample. Genus-level analysis revealed the most abundant genera for each brand's microbial community. The top 8 genera accounting for greater than $1 \%$ of the total abundance in at least 1 of the sampled brands of QF are shown in Table 4. The dominant genera in brand A were Thermus $(\sim 87.70 \%)$ and Streptococcus ( $>6.63 \%$; Table 4$)$. Streptococcus and Thermus were also the dominant genera in brand $\mathrm{C}$, but made up a lower percentage of the community when compared with brand A ( $\sim 30.81$ and $28.08 \%$ respectively). Anoxybacillus, a common dairy industry contaminant (Burgess et al., 2009; Goh et al., 2014), had a relative abundance of $13.38 \pm 5.06 \%$ in brand C. Anoxybacillus and Lactococcus were the dominant genera (both $>6 \%$ relative abundance) in brand $\mathrm{B}$. We also found 74,107 , and 83 additional genera detected in brands $\mathrm{A}, \mathrm{B}$, and $\mathrm{C}$, respectively. Each of these genera individually accounted for less than $1 \%$ of the total relative abundance of each cheese microbiome but collectively constituted approximately 3,45 , and $21 \%$ of the total abundance, respectively. Streptococcus is often a common starter pair with Lactobacillus in the production of pasteurized milk QF (Tunick and Van Hekken, 2010). Streptococcus has been shown to increase moisture retention in Manchego-type cheeses (Lluis-Arroyo et al., 2014) and the fresh HSC Panela (Jiménez-Guzmán et al., 2009). Thermus has been shown to enter cheese production facilities through hot water systems (Quigley et al.,

Table 4. Percentage of bacterial genera (\% total) in the sampled Queso Fresco ${ }^{1}$

\begin{tabular}{lccr}
\hline Genus & $\mathrm{A}$ & $\mathrm{B}$ & \multicolumn{1}{c}{$\mathrm{C}$} \\
\hline Acinetobacter & $0.30 \pm 0.09$ & $0.87 \pm 0.24$ & $3.41 \pm 1.03$ \\
Anoxybacillus & $0.05 \pm 0.02$ & $22.99 \pm 13.41$ & $13.38 \pm 5.06$ \\
Bacteroides & $0.02 \pm 0.01$ & $3.22 \pm 2.54$ & $0.09 \pm 0.05$ \\
Lactococcus & $0.14 \pm 0.03$ & $10.06 \pm 3.95$ & $0.33 \pm 0.12$ \\
Mycoplasma & $0.01 \pm 0.00$ & $6.31 \pm 4.11$ & $0.00 \pm 0.00$ \\
Pseudomonas & $0.30 \pm 0.19$ & $6.62 \pm 4.16$ & $4.94 \pm 1.25$ \\
Streptococcus & $8.63 \pm 1.47$ & $4.39 \pm 2.60$ & $30.81 \pm 8.53$ \\
Thermus & $87.70 \pm 1.44$ & $0.04 \pm 0.01$ & $28.08 \pm 5.43$ \\
Other & 2.85 & 45.5 & 20.99 \\
\hline
\end{tabular}

${ }^{1} \mathrm{~A}: \mathrm{n}=8, \mathrm{~B}: \mathrm{n}=8, \mathrm{C}: \mathrm{n}=6$. Values are means \pm SEM. Bacterial genera $>1 \%$ in at least 1 brand of Queso Fresco.
2016), which may suggest that the dominant bacterial genera from brand $\mathrm{A}$ is a contaminant; however, further testing would be required by the cheese manufacturer to determine if this is the case. Thermus is often associated with a pink defect in cheeses, but QF shelf life is not long enough for the pink discoloration to be a problem.

Principal coordinate analysis of the QF microbiota revealed substantial clustering of the microbiota for each brand regardless of lot (Figure 1A). The individual packages (subscript 1 or 2 ) within each lot were also highly clustered, with only a single package from the second lot of brand B being far from its counterpart. Together, with the selected chemical analyses and microbial culture results, these results show that the cheeses were quite homogeneous within each lot. It is tempting to suggest that microbial community profiling could be used by QF producers as an additional tool to confirm they have a consistent process and identify when there is a production deviation (due to seasonality, milk sourcing, improper cleaning, and so on) when this analysis is more economically feasible for producers. Although it is pointless to pinpoint the current cost of microbial community sequencing, as it is rapidly decreasing, a recent review highlighted how the plummeting cost of sequencing and rising level of data interpretation is resulting in the value of microbial monitoring of food and food preparation systems justifying the expense for manufacturers (Bokulich et al., 2016).

Additionally, we were able to compare the dissimilarities among the brands and lots by measuring the phylogenetic distances between sets of bacterial taxa using UniFrac (Figure 1B). The lots within each brand had less UniFrac distance than between brands, highlighting the temporal consistency of each brands microbial community. Both brands A and B were labeled as having added cultures or being produced with cultured milk; however, the dominant genera from these brands did not indicate that this was a reason for their tight clustering. The overwhelming similarity within brand A was likely due to the consistent dominance of Thermus present in each of the samples (Table 4). The $\alpha$ diversity analysis revealed a significant increase in the microbial diversity and richness, as measured by the number of operational taxonomic units, Chao1 (richness of total bacterial taxa in each brand), Shannon (the abundance and evenness of the bacterial taxa), and Simpson (the relative abundance of each taxon) indices of brands B and $\mathrm{C}$ compared with brand A (Table 5). It would be valuable for the facility to perform microbial profiling at different locations to determine if the microbial population was endemic to the facility or was the result 
Table 5. Alpha-diversity of cheese microbiota ${ }^{1,2,3,4}$

\begin{tabular}{|c|c|c|c|c|}
\hline Brand & Chao1 & $\begin{array}{l}\text { Observed operational } \\
\text { taxonomic unit }\end{array}$ & Shannon & Simpson \\
\hline $\begin{array}{l}\mathrm{A}(\mathrm{n}=8) \\
\mathrm{B}(\mathrm{n}=8) \\
\mathrm{C}(\mathrm{n}=6)\end{array}$ & $\begin{array}{l}120.44^{\mathrm{a}} \pm 13.56 \\
306.46^{\mathrm{b}} \pm 49.04 \\
314.69^{\mathrm{b}} \pm 34.35\end{array}$ & $\begin{array}{c}59.63^{\mathrm{a}} \pm 5.81 \\
182.88^{\mathrm{b}} \pm 25.24 \\
163.17^{\mathrm{b}} \pm 20.47\end{array}$ & $\begin{array}{l}1.35^{\mathrm{a}} \pm 0.07 \\
4.41^{\mathrm{b}} \pm 0.63 \\
3.60^{\mathrm{b}} \pm 0.32\end{array}$ & $\begin{aligned} 0.37^{\mathrm{a}} & \pm 0.02 \\
0.77^{\mathrm{b}} & \pm 0.10 \\
0.79^{\mathrm{ab}} & \pm 0.05\end{aligned}$ \\
\hline \multicolumn{5}{|c|}{$\begin{array}{l}\text { a,b Values within columns with dissimilar letters are significantly different }(P<0.05) \text { when compared using } \\
\text { Dunn's test. } \\
{ }^{1} \text { Microbiota from cheese }(\mathrm{n}=24 \text {, see Figure } 1) \text {. } \\
{ }^{2} \text { Microbial analysis by Illumina } 16 \mathrm{~S} \text { rRNA gene sequencing (V3-V5 hypervariable region; Illumina Inc., San } \\
\text { Diego, CA). } \\
{ }^{3} \text { Rarefaction was calculated based on } 3,110 \text { sequences per sample when the maximum number of operational } \\
\text { taxonomic units were observed in all groups. }\end{array}$} \\
\hline
\end{tabular}

of the different raw material suppliers used by each QF producer. In addition, it is unknown how these different microbial communities influenced the sensorial qualities of each brand. Regardless, QF manufacturers can potentially use microbial profiling as an additional tool to confirm a consistent product is being produced.

\section{CONCLUSIONS}

This work provides $\mathrm{pH}$, salt content, moisture content, and microbial characterizations for a set of QF. The cheeses showed little variation in their $\mathrm{pH}$, salt content, and moisture content, falling within previously reported ranges. However, the cheeses labeled as having added cultures tested among the lowest for LAB. Yeast and molds tested below the detection limit for all cheeses, and the fourth lot of 3 brands had cheeses that tested positive for coliforms, potentially due to postprocessing contamination or mishandling. We showed that all of the sampled cheeses were suitable substrates for L. monocytogenes growth. Lastly, microbial profiling over several lots of 3 cheese brands revealed that each $\mathrm{QF}$ has a unique microbial fingerprint that is consistent across lots yet distinct from other brands. As the price of sequencing decreases, analyzing the microbial community over lots may help manufacturers determine quality control issues more readily than culture-based methods.

\section{ACKNOWLEDGMENTS}

We thank Jennifer L. Hoeflinger (University of Illinois, Urbana-Champaign) for consultation on microbial data analysis as well as Susannah Miller and Suneet R. Takhar (University of Illinois, Urbana-Champaign) for their assistance in the laboratory. Additionally, we thank Hannah Holscher, Ravikiran Donthu, Celia Mé- ndez, and Mark C. Bell (University of Illinois, UrbanaChampaign) for their help with the 16s rRNA gene sequencing and analysis. We also thank CONACYT (National Council for Science and Technology, Mexico City, Mexico) for the PhD scholarship for LAIS and Bonnie Puls Raths for the fellowship for MJH. Finally, we thank the University of Illinois College of Agricultural, Consumer and Environmental Sciences and CONACYT for providing research funds.

\section{REFERENCES}

Aldrete-Tapia, A., M. C. Escobar-Ramírez, M. L. Tamplin, and M. Hernández-Iturriaga. 2014. High-throughput sequencing of microbial communities in Poro cheese, an artisanal Mexican cheese. Food Microbiol. 44:136-141.

AOAC International. 2012. Official Methods of Analysis of AOAC International. 17th ed. AOAC International Gaithersburg, MD.

Barry, K. A., D. Hernot, I. Middelbos, C. Francis, B. Dunsford, K. Swanson, and G. Fahey. 2009. Low-level fructan supplementation of dogs enhances nutrient digestion and modifies stool metabolite concentrations, but does not alter fecal microbiota populations. J. Anim. Sci. 87:3244-3252.

Batz, M. B., S. A. Hoffmann, and J. G. Morris. 2011. Ranking the risks: The 10 pathogen-food combinations with the greatest burden on public health. Emerging Pathogens Institute, University of Florida, Gainesville.

Bevilacqua, A., B. Speranza, M. Gallo, and M. R. Corbo. 2017. A new frontier for starter cultures: Attenuation and modulation of metabolic and technological performance. Pages 148-161 in Starter Cultures in Food Production. B. Speranza, A. Bevilacqua, M. R. Corbo, and M. Sinigaglia, ed. John Wiley \& Sons Ltd., Chichester, UK.

Bokulich, N. A., Z. T. Lewis, K. Boundy-Mills, and D. A. Mills. 2016. A new perspective on microbial landscapes within food production. Curr. Opin. Biotechnol. 37:182-189.

Bokulich, N. A., and D. A. Mills. 2013. Facility-specific "house" microbiome drives microbial landscapes of artisan cheesemaking plants. Appl. Environ. Microbiol. 79:5214-5223.

Bolton, L. F., and J. F. Frank. 1999. Defining the growth/no-growth interface for Listeria monocytogenes in Mexican-style cheese based on salt, pH, and moisture content. J. Food Prot. 62:601-609.

Buchanan, R. L., W. G. Damert, R. C. Whiting, and M. van Schothorst. 1997. Use of epidemiologic and food survey data to estimate a purposefully conservative dose-response relationship for 
Listeria monocytogenes levels and incidence of listeriosis. J. Food Prot. 60:918-922.

Burgess, S. A., J. Brooks, J. Rakonjac, K. Walker, and S. Flint. 2009. The formation of spores in biofilms of Anoxybacillus flavithermus. J. Appl. Microbiol. 107:1012-1018.

Campagnollo, F. B., L. P. Margalho, B. A. Kamimura, M. D. Feliciano, L. Freire, L. S. Lopes, V. O. Alvarenga, V. A. Cadavez, U. Gonzales-Barron, and D. W. Schaffner. 2018. Selection of indigenous lactic acid bacteria presenting anti-listerial activity, and their role in reducing the maturation period and assuring the safety of traditional Brazilian cheeses. Food Microbiol. 73:288-297.

Caporaso, J. G., J. Kuczynski, J. Stombaugh, K. Bittinger, F. D. Bushman, E. K. Costello, N. Fierer, A. G. Peña, J. K. Goodrich, and J. I. Gordon. 2010. QIIME allows analysis of high-throughput community sequencing data. Nat. Methods 7:335-336.

CDC. 2017a. List of Selected Multistate Foodborne Outbreak Investigations. Vol. 2017. Centers for Disease Control and Prevention (CDC), Atlanta, Ga.

CDC. 2017b. People At Risk. Vol. 2017. Accessed Oct. 1, 2017. https://www.cdc.gov/listeria/risk.html.

Ercolini, D. 2013. High-throughput sequencing and metagenomics: Moving forward in the culture-independent analysis of food microbial ecology. Appl. Environ. Microbiol. 79:3148-3155.

Feng, P., S. D. Weagant, M. A. Grant, W. Burkhardt, M. Shellfish, and B. Water. 2002. BAM: Enumeration of Escherichia coli and the coliform bacteria. Accessed Oct. 1, 2017. https://www.fda.gov/ Food/FoodScienceResearch/LaboratoryMethods/ucm064948.htm.

Ferreira, V., M. Wiedmann, P. Teixeira, and M. Stasiewicz. 2014. Listeria monocytogenes persistence in food-associated environments: Epidemiology, strain characteristics, and implications for public health. J. Food Prot. 77:150-170.

Fox, P. F., T. P. Guinee, T. M. Cogan, and P. L. H. McSweeney. 2017. Microbiology of cheese ripening. Pages 333-390 in Fundamentals of Cheese Science. P. F. Fox, T. P. Guinee, T.M. Cogan, and P. L. H. McSweeney, ed. Springer, Boston, MA.

Genigeorgis, C., M. Carniciu, D. Dutulescu, and T. B. Farver. 1991. Growth and survival of Listeria monocytogenes in market cheeses stored at 4 to 30 C. J. Food Prot. 54:662-668.

Gillespie, B. E., M. Lewis, S. Boonyayatra, M. Maxwell, A. Saxton, S. Oliver, and R. Almeida. 2012. Evaluation of bulk tank milk microbiological quality of nine dairy farms in Tennessee. J. Dairy Sci. 95:4275-4279.

Goh, K. M., H. M. Gan, K.-G. Chan, G. F. Chan, S. Shahar, C. S. Chong, U. M. Kahar, and K. P. Chai. 2014. Analysis of Anoxybacillus genomes from the aspects of lifestyle adaptations, prophage diversity, and carbohydrate metabolism. PLoS One 9:e90549.

Hitchins, A. D., K. Jinneman, and Y. Chen. 2017. BAM: Detection and enumeration of Listeria monocytogenes. Accessed Oct. 1, 2017. https://www.fda.gov/food/foodscienceresearch/ laboratorymethods/ucm071400.htm.

Hnosko, J., S. Clark, and D. Van Hekken. 2008. Latin American cheeses. Pages 489-504 in The Sensory Evaluation of Dairy Products. S. Clark, M. Costello, M. Drake, and F. Bodyfelt, ed. Springer US, New York, NY.

Hnosko, J., M. S.-M. Gonzalez, and S. Clark. 2012. High-pressure processing inactivates Listeria innocua yet compromises Queso Fresco crumbling properties. J. Dairy Sci. 95:4851-4862.

Ibarra-Sánchez, L. A., M. L. Van Tassell, and M. J. Miller. 2017. Invited review: Hispanic-style cheeses and their association with Listeria monocytogenes. J. Dairy Sci. 100:2421-2432.

Ibarra-Sánchez, L. A., M. L. Van Tassell, and M. J. Miller. 2018. Antimicrobial behavior of phage endolysin PlyP100 and its synergy with nisin to control Listeria monocytogenes in Queso Fresco. Food Microbiol. 72:128-134

Jeraldo, P., K. Kalari, X. Chen, J. Bhavsar, A. Mangalam, B. White, H. Nelson, J.-P. Kocher, and N. Chia. 2014. IM-TORNADO: A tool for comparison of $16 \mathrm{~S}$ reads from paired-end libraries. PLoS One 9:e114804.

Jiménez-Guzmán, J., A. Flores-Nájera, A. E. Cruz-Guerrero, and M. García-Garibay. 2009. Use of an exopolysaccharide-producing strain of Streptococcus thermophilus in the manufacture of Mexican Panela cheese. Lebensm. Wiss. Technol. 42:1508-1512.

Kilonzo-Nthenge, A., F.-C. Chen, and S. L. Godwin. 2008. Occurrence of Listeria and Enterobacteriaceae in domestic refrigerators. J. Food Prot. 71:608-612.

Lê, S., J. Josse, and F. Husson. 2008. FactoMineR: An R package for multivariate analysis. J. Stat. Softw. 25:1-18.

Leggett, L., P. Tomasula, D. Van Hekken, A. Porto-Fett, B. Shoyer, J. Renye, J. Luchansky, and N. Farkye. 2012. Effect of storage at 4 and $10 \mathrm{C}$ on the growth of Listeria monocytogenes in and on Queso Fresco. J. Food Saf. 32:236-245.

Liu, X., Y. Wang, J. L. Hoeflinger, B. P. Neme, E. H. Jeffery, and M. J. Miller. 2017. Dietary broccoli alters rat cecal microbiota to improve glucoraphanin hydrolysis to bioactive isothiocyanates. Nutrients 9:262

Lluis-Arroyo, D., A. Flores-Nájera, A. Cruz-Guerrero, F. GallardoEscamilla, C. Lobato-Calleros, J. Jiménez-Guzmán, and M. García-Garibay. 2014. Effect of an exopolysaccharide-producing strain of Streptococcus thermophilus on the yield and texture of Mexican Manchego-type cheese. Int. J. Food Prop. 17:1680-1693.

Macías-Rodríguez, M. E., V. Navarro-Hidalgo, J. Linares-Morales, M. Olea-Rodriguez, A. Villarruel-López, J. Castro-Rosas, C. GomezAldapa, and M. Torres-Vitela. 2013. Microbiological safety of domestic refrigerators and the dishcloths used to clean them in Guadalajara, Jalisco, Mexico. J. Food Prot. 76:984-990.

Mendoza-Yepes, M. J., O. Abellan-Lopez, J. Carrion-Ortega, and F. Marin-Iniesta. 1999. Inhibition of Listeria monocytogenes and other bacteria in Spanish soft cheese made with Lactococcus lactis ssp. diacetylactis. J. Food Saf. 19:161-170.

Montel, M.-C., S. Buchin, A. Mallet, C. Delbes-Paus, D. A. Vuitton, N. Desmasures, and F. Berthier. 2014. Traditional cheeses: rich and diverse microbiota with associated benefits. Int. J. Food Microbiol. 177:136-154.

Muturi, E. J., R. K. Donthu, C. J. Fields, I. K. Moise, and C.-H. Kim. 2017. Effect of pesticides on microbial communities in container aquatic habitats. Sci. Rep. 7:44565.

NACMCF. 2015. Response to Questions Posed by the Department of Defense Regarding Microbiological Criteria as Indicators of Process Control or Sanitary Conditions. National Advisory Committee on Microbiological Criteria from Foods. Accessed Oct 5, 2017. https://www.fsis.usda.gov/wps/wcm/connect/2ea3f473-cd12-4333 -a28e-b2385454c967/NACMCF-Report-Process-Control-061015 .pdf?MOD=AJPERES.

Quast, C., E. Pruesse, P. Yilmaz, J. Gerken, T. Schweer, P. Yarza, J. Peplies, and F. O. Glöckner. 2013. The SILVA ribosomal RNA gene database project: Improved data processing and web-based tools. Nucleic Acids Res. 41(D1):D590-D596.

Quigley, L., D. J. O'Sullivan, D. Daly, O. O'Sullivan, Z. Burdikova, R. Vana, T. P. Beresford, R. P. Ross, G. F. Fitzgerald, and P. L. McSweeney. 2016. Thermus and the pink discoloration defect in cheese. mSystems 1:e00023-16. https://doi.org/10.1128/mSystems .00023-16.

Quigley, L., O. O'Sullivan, T. P. Beresford, R. P. Ross, G. F. Fitzgerald, and P. D. Cotter. 2012. High-throughput sequencing for detection of subpopulations of bacteria not previously associated with artisanal cheeses. Appl. Environ. Microbiol. 78:5717-5723.

Renye, J. A., G. A. Somkuti, B. Vallejo Cordoba, D. L. Van Hekken, and A. F. Gonzalez Cordova. 2008. Characterization of the microflora isolated from Queso Fresco made from raw and pasteurized milk. J. Food Saf. 28:59-75.

Saxer, S., S. M. Schwenninger, and C. Lacroix. 2013. Characterization of the microflora of industrial Mexican cheeses produced without added chemical preservatives. Lebensm. Wiss. Technol. 53:314320 .

Secretaria de Salud. 2010. NOM-243-SSA1-2010. Leche, formula lactea, producto lacteo combinado y derivados lacteos. Disposiciones y especificaciones. D.F. Secretaria de Salud, Mexico City, Mexico.

Tournas, V., M. Stack, P. Mislivec, H. Koch, and R. Bandler. 2001. Yeasts, molds and mycotoxins. Pages 227-234 (Chapter 18) in 
Bacteriological Analytical Manual (BAM). Food and Drug Administration, Gaithersburg, MD.

Trmčić, A., K. Chauhan, D. Kent, R. Ralyea, N. Martin, K. Boor, and M. Wiedmann. 2016. Coliform detection in cheese is associated with specific cheese characteristics, but no association was found with pathogen detection. J. Dairy Sci. 99:6105-6120.

Tunick, M. H., and D. L. Van Hekken. 2010. Rheology and texture of commercial queso fresco cheeses made from raw and pasteurized milk. J. Food Qual. 33(s1):204-215.

US Census Bureau. 2017. Facts for Features: Hispanic Heritage Month 2017. Accessed Jul. 19, 2017. https://www.census.gov/newsroom/ facts-for-features/2017/hispanic-heritage.html.

USDA-NASS. 2016. Dairy products 2016 summary. Vol. 2017, USDANational Agriculture Statistics Service, Washington, DC.

Van Hekken, D. L., and N. Y. Farkye. 2003. Hispanic cheeses: The quest for queso. Food Technol. 57:32-38.
Van Tassell, M. L., L. A. Ibarra-Sánchez, G. P. Hoepker, and M. J. Miller. 2017. Hot topic: Antilisterial activity by endolysin PlyP100 in fresh cheese. J. Dairy Sci. 100:2482-2487.

Van Tassell, M. L., L. A. Ibarra-Sanchez, S. R. Takhar, S. L. AmayaLlano, and M. J. Miller. 2015. Use of a miniature laboratory fresh cheese model for investigating antimicrobial activities. J. Dairy Sci. 98:8515-8524.

Wolfe, B. E., J. E. Button, M. Santarelli, and R. J. Dutton. 2014. Cheese rind communities provide tractable systems for in situ and in vitro studies of microbial diversity. Cell 158:422-433.

Yu, Z., and M. Morrison. 2004. Improved extraction of PCR-quality community DNA from digesta and fecal samples. Biotechniques $36: 808-812$. 